\title{
Armoede effectief bestrijden
}

\author{
Author(s) \\ van Geuns, R.C.; Stallen, Mirre \\ Publication date \\ 2021 \\ Document Version \\ Final published version \\ Published in \\ Vakblad Sociaal Werk
}

Link to publication

Citation for published version (APA):

van Geuns, R. C., \& Stallen, M. (2021). Armoede effectief bestrijden. Vakblad Sociaal Werk, 2021(6), 7-11.

It is not permitted to download or to forward/distribute the text or part of it without the consent of the author(s) and/or copyright holder(s), other than for strictly personal, individual use, unless the work is under an open content license (like Creative Commons).

\section{Disclaimer/Complaints regulations}

If you believe that digital publication of certain material infringes any of your rights or (privacy) interests,

please let the Library know, stating your reasons. In case of a legitimate complaint, the Library will make the material inaccessible and/or remove it from the website. Please contact the library:

https://www.amsterdamuas.com/library/contact/questions, or send a letter to: University Library (Library of the University of Amsterdam and Amsterdam University of Applied Sciences), Secretariat, Singel 425, 1012 WP Amsterdam, The Netherlands. You will be contacted as soon as possible. 


\section{Armoede effectief bestrijden}

Door Roeland van Geuns \& Mirre Stallen

Zowel in het beleid om armoede tegen te gaan als in maatschappelijke denkbeelden over armoede zijn een aantal zaken ten goede veranderd. Dat betekent niet dat we nu wel op onze handen kunnen gaan zitten. Het aantal huishoudens dat met armoede en schulden kampt, stijgt immers nog steeds. Roeland van Geuns en Mirre Stallen zetten uiteen wat er volgens hen nog meer nodig is om daadwerkelijk een eind te maken aan armoede en schuldenproblematiek.

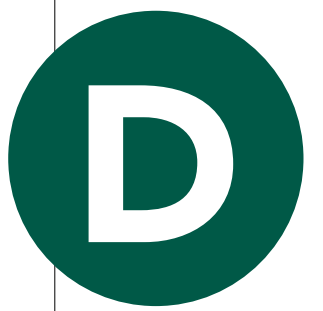

Tien jaar geleden beweerde minister-president Mark Rutte in een interview met het Algemeen Dagblad dat armoede in Nederland niet bestaat. Armoede zou een verschijnsel zijn dat zich voordoet in Afrika en India, maar in Nederland gaat niemand dood van de honger, aldus Rutte. Meer recent zei toenmalig staatssecretaris Tamara van Ark dat kinderen vanaf 2030 niet meer zouden mogen opgroeien met de gevolgen van armoede. Daarmee erkende ze, zij het impliciet, dat armoede in Nederland wel degelijk een probleem is. Wat is er in tien jaar veranderd? En waar staan we op het terrein van beleid en uitvoering gericht op het terugdringen en voorkomen van armoede? Deze vragen proberen wij in deze bijdrage te beantwoorden.

\section{Verrassend}

In 2010 bevond Nederland zich in het oog van een orkaan: de financiële crisis liep op zijn eind, maar de economische crisis en de daarmee samenhangende grote werkloosheid moesten nog beginnen. Ons land kwam uit een periode van ongekende economische groei en een historisch lage werk- loosheid. Armoede zoals gedefinieerd door het CBS lag in 2010 op een historisch laag niveau: 7,4 procent van de Nederlandse huishoudens leefde van een laag inkomen (Sociaal Cultureel Planbureau, 2019). In de jaren na 2010, dus tijdens en in de nasleep van de economische crisis, steeg de armoede (zie figuur 1). Na de economische crisis daalde het armoedeniveau weer tot het niveau van voor de crisis, maar van een verdere daling was geen sprake. Dit is verrassend, omdat er in die jaren sprake was van vrij forse economische groei en een stijging van het BNP.

Betekenen deze data dat het na de economische crisis gevoerde beleid geen impact heeft gehad op armoede in Nederland? Enerzijds is de manier waarop beleidsmakers, uitvoerders en professionals naar armoede kijken ten goede veranderd en zijn er enkele hoopgevende beleidswijzigingen in gang gezet. Dat we in de macro-cijfers niettemin relatief weinig structurele verandering zien, komt voort uit belangrijke beleidsfactoren die (nog) niet veranderd zijn en door maatschappelijke denkbeelden over armoede. Hieronder lichten we dat verder toe. Ook gaan we in op de vraag welke veranderingen er nog meer nodig zijn om armoede en schuldenproblematiek daadwerkelijk terug te dringen. 


\section{Denkbeelden over armoede}

In 2013 verscheen het boek Schaarste. Hoe gebrek aan tijd en geld ons gedrag bepalen (Mullainathan \& Shafir, 2013). Dit boek vond snel een vrij groot lezerspubliek. De meest fundamentele boodschap ervan was: mensen zijn niet arm als gevolg van hun handelen, maar hun handelen is veelal gevolg van hun armoede. Het boek bracht een omslag teweeg in de wijze waarop beleidsmakers en professionals naar de oorzaken van armoede keken.

Eerder werd veelal gedacht dat mensen arm zijn vanwege onverantwoorde bestedingspatronen ('dom handelen') en dus zelf verantwoordelijk zijn voor hun situatie. Uitgangspunt van het nieuwe denken is dat het juist de ervaring en de gevolgen van armoede zijn die mensen ertoe brengen om kortetermijnbeslissingen te nemen: zij kúnnen simpelweg geen rekening houden met de langetermijngevolgen van sommige van hun keuzes. Het gevolg is dat hun armoede (en niet zelden hun schulden) door dit handelen alleen maar toenemen. De conclusie van Schaarste en van wetenschappelijke studies die aan het boek ten grondslag liggen, is dat we niet naar armoede moeten kijken als resultaat van individueel menselijk handelen. Als we ons richten op de fundamentele oorzaken van armoede en díe aanpakken, krijgen mensen letterlijk weer de ruimte om ander gedrag aan de dag te leggen. Ook 'Schuldig', een spraakmakende documentaireserie van Human, heeft invloed gehad op de manier waarop in Nederland naar armoede en de oorzaken daarvan wordt gekeken. De documentaire speelt zich af in de Vogelbuurt in Amsterdam-Noord en draait om een aantal bewoners van die buurt met schulden, maar ook om de werelden daaromheen: die van de deurwaarder, de hulpverlener, de schuldeiser en de lokale politiek. 'Schuldig' maakt inzichtelijk en voelbaar hoe groot de gevolgen van schulden en armoede zijn voor het alledaagse leven van mensen en hoe moeilijk het, gegeven het Nederlandse beleid rondom schuldenproblematiek, is eruit te ontsnappen. $\mathrm{Na}$ de tv-uitzending van de documentaire in 2016 was een sterke toename te zien in maatschappelijke aandacht voor armoede en groeide het aantal beleidsinitiatieven gericht op het terugdringen van armoede en schulden.

\section{Veranderingen ten goede}

Investeringen die de overheid in de afgelopen tien jaar gedaan heeft in het terugdringen van armoede- en schuldenproblematiek hebben onder meer geleid tot verschillende landelijke samenwerkingsverbanden en initiatieven, waaronder Schuldenlab070, SchuldenlabNL, de Alliantie Kinderarmoede, de Nederlandse Schuldhulproute en de Schuldeiserscoalitie. Ook zijn er landelijke publiekscampagnes gevoerd. 'Kom uit je schuld' en 'Kom jij eruit?' bijvoorbeeld, waren gericht op het tegengaan van schaamte over armoede en schulden. Ook zijn er honderden andere, meer kleinschalige initiatieven opgezet met als doel armoede en schulden terug te dringen (Van Geuns et al., 2021).

Daarnaast veranderde in de regelgeving het een en ander. Zo paste de overheid begin dit jaar de Wet gemeentelijke schuldhulpverlening zodanig aan dat het leveranciers - nutsbedrijven, woningbouwverenigingen, verzekeraars - verplicht om huishoudens met beginnende betalingsachterstanden in hun vaste lasten te melden bij gemeenten. Die laatste zijn vervolgens verplicht om met de betreffende huishoudens na te gaan hoe deze betalingsachterstanden kunnen worden ingelopen. Deze wetswijziging heeft als doel om de grote schulden die op termijn kunnen ontstaan te voorkomen. Lokaal zijn er meer voorbeelden te vinden van beleidswijzigingen die de druk op lage inkomensgroepen verminderen. Zo worden gemeentelijke heffingen in een aantal gemeenten automatisch kwijtgescholden als iemand bijvoorbeeld een bijstandsuitkering ontvangt. Deze mensen hoeven deze kwijtschelding daardoor niet steeds opnieuw zelf aan te vragen. De regeling ontlast niet alleen mensen, maar ondervangt ook het probleem dat mensen soms niet op de hoogte zijn van deze mogelijkheid tot kwijtschelding, of niet in staat zijn om die aan te vragen. Ook zijn er verschillende gemeenten die het mogelijk hebben gemaakt dat mensen met een bijstandsinkomen (hogere) giften mogen ontvangen, zodat deze groep jaarlijks ook enige (financiële) steun van anderen kan ontvangen. Een laatste voorbeeld betreft gemeenten die schulden van bepaalde groepen, zoals mensen met geestelijke gezondheidsklachten, opkopen en kwijtschelden. De gemeenschappelijke noemer van 
Armoede bereikte piek in 2013, maar neemt daarna flink af

(Personen in armoede, 2011-2017 (in aantallen x 1000 en in procenten van de bevolking)

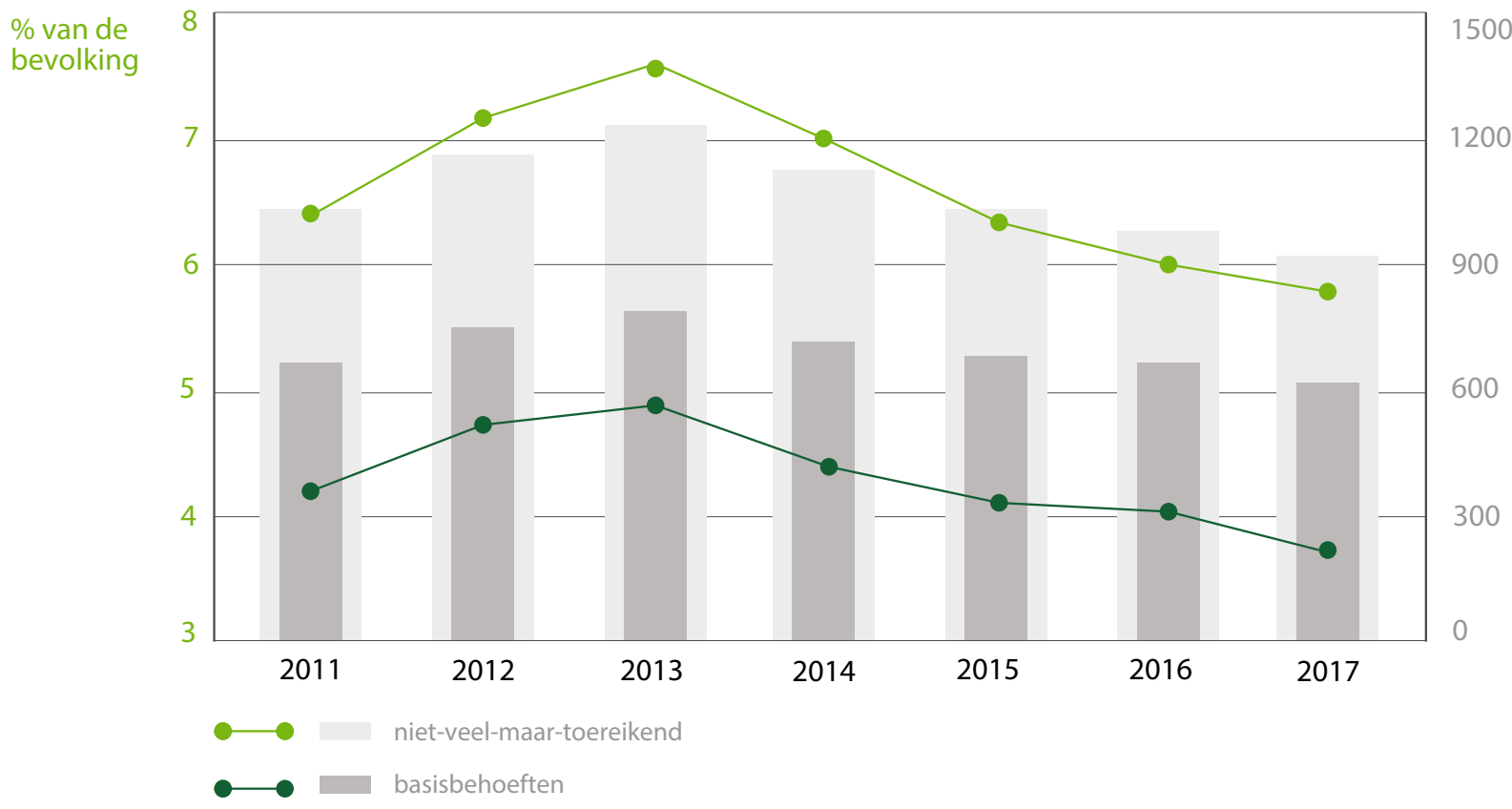

Bron: CBS (Integrale inkomens- en vermogensstatistiek '11-'17), SCP-bewerking

Figuur 1. Het basisbehoeftenbudget omvat de minimale uitgaven van een zelfstandig huishouden aan onvermijdbare, basale zaken als voedsel, kleding en wonen. Het nietveel-maar-toereikend budget includeert ook de minimale kosten van ontspanning en sociale participatie.Van armoede is niet alleen sprake wanneer er een laag inkomen is zonder vrij opneembaar vermogen. Armoede kan ook aanwezig zijn wanneer een (wat) hoger inkomen gepaard gaat met schulden waarvan het aflossen ten koste gaat van het vrij besteedbaar inkomen. De armoede die hierdoor wordt veroorzaakt is in deze figuur niet weergegeven.

deze vernieuwingen is dat de betrokkenen per saldo over een iets ruimer budget kunnen beschikken en minder snel in de knel komen met beleidsregels.

\section{Verbeterde communicatie}

Tot slot zien we dat (gemeentelijke) organisaties hun communicatie met burgers steeds vaker verbeteren. Schriftelijke communicatie (denk aan brieven, websites, e-mails, (digitale) aanvraagformulieren) wordt aangepast en vereenvoudigd. Dit is van belang omdat ingewikkeld taalgebruik en complexe aanvraagprocedures er veelal toe leiden dat mensen die daar wel recht op hebben, geen gebruik maken van (gemeentelijke) aanvullende inkomensregelingen. Ook is er binnen organisaties groeiende aandacht voor mondelinge communicatie. Zo krijgen professionals regelmatig training in motiverende gespreksvoering en stress-sensitief werken (Jungmann et al., 2020). Overigens blijkt daarbij het eenmalig trainen van uitvoerders vaak onvoldoende. Naast het technisch aanleren van betere gesprekstechnieken is het noodzakelijk dat de volledige organisatie inzet op een aanpak waarbij vertrouwen in en oprechte belangstelling en respect voor klanten centraal staan. Als van dat laatste geen sprake is, is motiverende gespreksvoering een loze techniek: er zijn dan nog steeds factoren die effectieve hulpverlening in de weg staan.

\section{De menselijke maat}

We hebben nu laten zien dat er zowel in het denken over armoede als in beleid om armoede terug te dringen een aantal zaken ten goede is veranderd. Betekent dat nu ook dat er genoeg gedaan is? Het antwoord op die vraag kan natuurlijk alleen maar ontkennend zijn. Daarvoor hebben nog te veel huishoudens te maken met armoede en schulden. Hieronder beschrijven we welke veranderingen er nog meer nodig zijn om armoede en schuldenproblematiek verder terug te dringen.

Het ontbreekt in de uitvoering van beleid vaak aan het toepassen van de 'menselijke maat': beleidsuitvoerders denken er vaak niet aan om naar de specifieke omstandigheden van een huishouden te kijken, of krijgen daartoe niet de ruimte. Een politieagent heeft bijvoorbeeld de vrijheid om iemand 


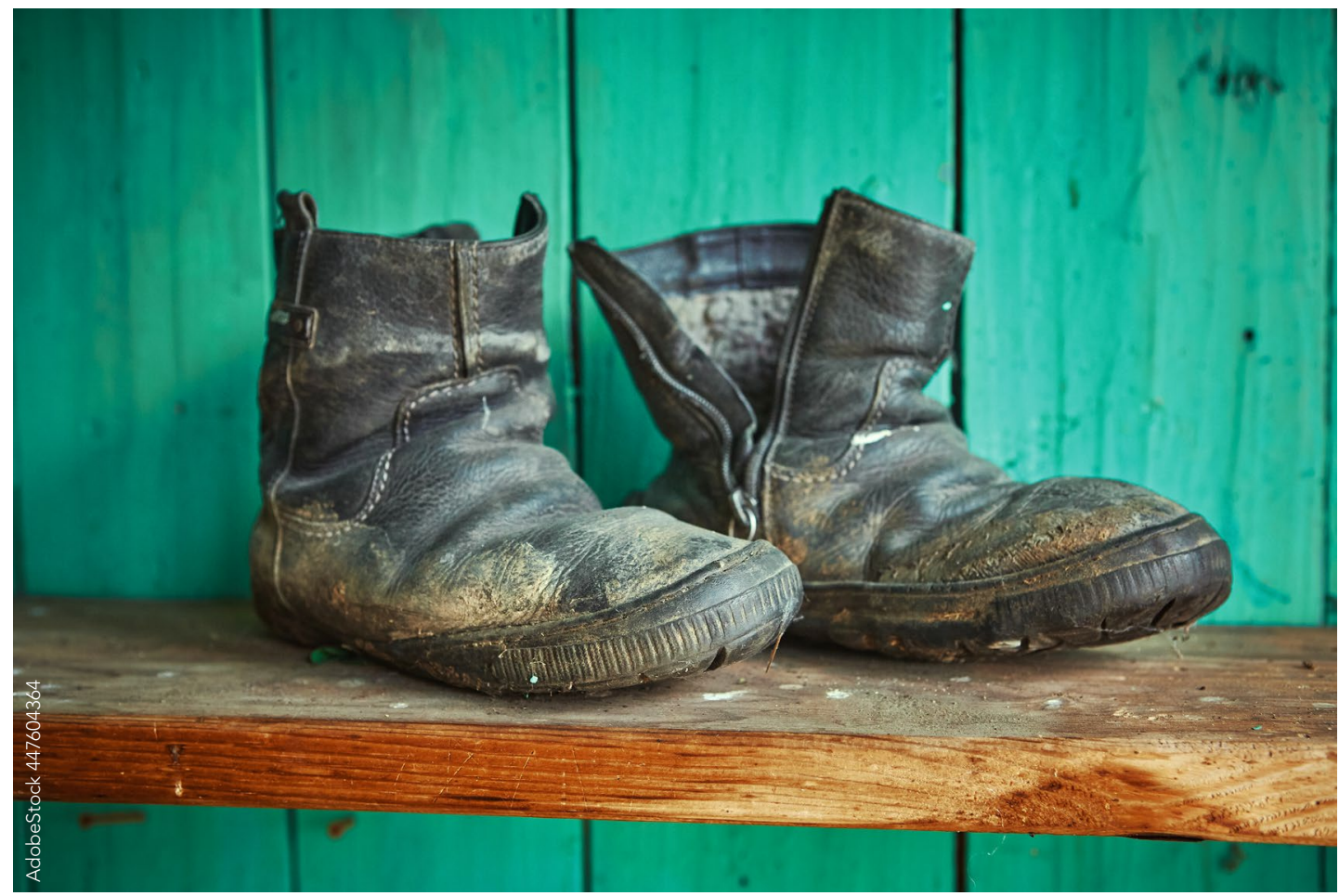

die fout geparkeerd staat of door rood licht rijdt, op grond van specifieke omstandigheden, geen boete te geven. Die 'menselijke maat' zou bij de uitvoering van wet- en regelgeving in het sociaal domein ook het uitgangspunt moeten zijn, maar is dat tot op heden niet.

Dit wordt schrijnend geillustreerd met de toeslagenaffaire, waar zowel in de wetgeving als in de uitvoering 'de menselijke maat' volledig zoek was (Frederik, 2021; Parlementaire ondervragingscommissie Kinderopvangtoeslag, 2020; Werkgroep reflectie toeslagenaffaire rechtbanken. Raad voor de Rechtspraak, 2021). Een belangrijke oorzaak van deze affaire is het rechtlijnig toepassen van algemene regels zonder oog te hebben voor de gevolgen van deze regels voor individuele huishoudens. Iets dergelijks is zichtbaar bij de toepassing van de Participatiewet. Deze wet moet erin resulteren dat ook mensen met een arbeidsbeperking werk vinden, maar laat weinig tot geen ruimte voor aanpassing in de uitvoering. Een voorbeeld hiervan is de 'boodschappenaffaire': een bijstandsgerechtigde vrouw werd veroordeeld tot het terugbetalen van een deel van haar bijstandsuitkering, omdat haar moeder geregeld boodschappen voor haar deed (zie: https:// uitspraken.rechtspraak.nl/inziendocument?id=ECLI:NL:CRVB:2021:1918). Deze zaak leidde tot veel publieke verontwaardiging en toonde wederom dat het in de uitvoering van beleid ontbreekt aan maatwerk.

\section{Meer speelruimte}

Om maatwerk te kunnen leveren, zijn er veranderingen noodzakelijk in de wetgeving en in de systemen (ICT, protocollen, werkplannen) die worden gebruikt voor het uitvoeren daarvan. Het aanpassen van wetgeving, en met name het veranderen van systemen als bijvoorbeeld het belastingen- en toeslagensysteem, zal veel tijd kosten. Wellicht is het gemakkelijker om beleidsuitvoerders meer 'speelruimte' te geven: bijvoorbeeld om terug te vorderen bedragen niet altijd volledig terug te eisen.

Ook het gebruik van betalingsregelingen is gemakkelijker te maken. Organisaties sturen nu vaak een rekening voor de (terug) betaling van een volledig bedrag. In plaats daarvan kunnen ze ook standaard een (terug) betaling in termijnen voorstellen. Het staat mensen uiteraard vrij het bedrag wel in één keer (terug) te betalen. Uitvoerders meer vrijheid geven om te handelen in de geest van de wet zou niet alleen de uitvoering effectiever maken, maar ook bijdragen aan een groter vertrouwen van burgers in de overheid.

\section{Meer vertrouwen}

Wellicht het grootste probleem dat ten grondslag ligt aan falend armoedebeleid is het wantrouwen van de overheid jegens burgers. In het sociaal domein is veel beleid gestoeld op wantrouwen en in de afgelopen decennia heeft bij de uitvoering van diverse overheidsdiensten de controle van burgers een steeds centralere plek gekregen. Die nadruk op 
wantrouwen heeft er bijvoorbeeld toe geleid dat arme huishoudens allerlei formulieren moeten invullen om (financiële) ondersteuning te ontvangen en constant verantwoording moeten afleggen aan de gemeente of andere overheidsinstanties. Zelfs huishoudens die al jaren in dezelfde situatie leven, moeten keer op keer aantonen dat zij recht hebben op bepaalde gemeentelijke voorzieningen. Dit is frustrerend, want veel gegevens die nodig zijn om vast te stellen of een huishouden in aanmerking komt voor voorzieningen zijn bij gemeenten immers al bekend. Helaas laat de AVG-wetgeving het combineren van de relevante data vaak niet toe, waardoor burgers nog steeds onnodig belast worden met ingewikkelde en tijdrovende bureaucratische handelingen. Het lijkt in het belang van huishoudens met een laag inkomen om waarden als privacy aan de ene kant en die van bestaanszekerheid aan de andere kant in een fundamentele discussie eens tegen elkaar af te wegen.

\section{Gerichter beleid}

Overheidsinstanties en goede doelen- en vermogensfondsen financieren een schier oneindig aantal projecten rond armoede en schulden. Deze projecten zijn veelal lokaal van aard, worden afzonderlijk uitgevoerd en een gemeenschappelijk doel ontbreekt. Een meer gerichte aanpak zou de effectiviteit ervan kunnen vergroten. Lokale beleidsmakers en uitvoerders kijken ook maar zelden naar de effectiviteit van een aanpak. Van de meeste projecten rond armoede en schulden is dan ook niet bekend wat hun toegevoegde waarde is. Het is denkbaar dat een aantal ervan niet of nauwelijks bijdragen aan het terugdringen van armoede en schuldenproblematiek. Gemeenten en fondsen zouden meer kunnen sturen op impact en moeten stoppen met de financiering van projecten die hun meerwaarde niet willen of kunnen aantonen.

\section{Meer inkomen}

Armoede is uiteindelijk een absoluut of relatief tekort aan geld. Er is de laatste jaren een steeds sterkere samenhang ontstaan tussen schulden en een te beperkt vrij besteedbaar budget. De echte weg uit armoede loopt dan ook via een stijging van het besteedbaar inkomen. Dat kan structureel eigenlijk alleen worden beïnvloed via de arbeidsmarkt. We zien echter dat een relatief grote groep er niet in slaagt of niet de gelegenheid krijgt om zich een structurele plaats te verwerven op de arbeidsmarkt om daar een inkomen te verdienen dat substantieel boven het minimumloon uitkomt. Dit heeft deels te maken met de verregaande flexibilisering van de arbeidsmarkt en het oprukken van de platformeconomie (Uber, maaltijdbestellers, flitsboodschap- pendiensten, et cetera) en deels met het feit dat een deel van de beroepsbevolking niet over de competenties beschikt om zich een plek op de arbeidsmarkt te verwerven. Willen we armoede structureel omlaag dringen, dan is het noodzakelijk om zowel het minimumloon als het sociaal minimum fors te verhogen. Daarbij moet de overheid toeslagen natuurlijk niet in gelijke mate verlagen; dan verandert er immers nog steeds niets. De uitkomst van deze aanpassingen zal moeten zijn dat het vrij besteedbaar inkomen omhooggaat en dat vaste lasten een kleiner deel van het netto-inkomen gaan uitmaken.

\section{Ten slotte}

Zoals beschreven zijn er in de afgelopen tien jaar in Nederland om armoede tegen te gaan al veel belangrijke veranderingen in gang gezet. Die laten nog niet het gewenste effect zien. Niettemin denken wij dat ze een eerste aanzet zijn tot de omslag in denken en handelen die noodzakelijk is voor een structurele aanpak van armoede- en schuldenproblematiek. Om echt een eind te maken aan armoede zijn een aanpassing van het belastingen- en toeslagensysteem noodzakelijk, net als gerichter armoedebestrijdingsbeleid, waarin meer aandacht is voor de menselijke maat, meer ruimte bestaat in de uitvoering en waarin het vertrouwen in burgers centraal staat. Als we deze uitgangspunten opnemen in beleid en toepassen in de uitvoering en het minimuminkomen verhogen, hoeft er volgens ons in 2030 in Nederland geen kind meer op te groeien in armoede.

Roeland van Geuns is lector Armoede Interventies aan de Hogeschool van Amsterdam. Mirre Stallen is senior-onderzoeker bij het Lectoraat Armoede Interventies aan de Hogeschool van Amsterdam en universitair docent bij de afdeling Sociale, Economische en Organisatiepsychologie aan de Universiteit Leiden.

\section{Bronnen:}

- Frederik, J. (2021). Zo hadden we het niet bedoeld. De tragedie achter de toeslagenaffaire. de Correspondent

- Geuns, van, R., Mak, J., \& Boonstoppel, E. (2021). Van Schulden Naar Kansen. Weten wat werkt (R. Van Geuns, J. Mak, \& E. Boonstoppel (eds.)). Thoth

- Jungmann, N., Wesdorp, P., \& Madern, T. (2020). Stress-sensitief werken in het sociaal domein. Inzichten en praktische handvatten voor hulp- en dienstverleners. Bohn, Stafleu, Van Loghum

- Mullainathan, S., \& Shafir, E. (2013). Scarcity: Why Having Too Little Means So Much. Times Books

- Parlementaire ondervragingscommissie Kinderopvangtoeslag. (2020). Ongekend Onrecht. 132

- Sociaal Cultureel Planbureau. (2019). Armoede in kaart

- Werkgroep reflectie toeslagenaffaire rechtbanken. Raad voor de Rechtspraak. (2021). Recht vinden bij de rechtbank. Lessen uit kinderopvangtoeslagzaken 